\title{
THE RELATIONSHIP BETWEEN LIVEABILITY AND PRICE OF RESIDENTIAL HOUSES - A CASE STUDY OF SHENZHEN
}

\author{
$\mathrm{Lu} \mathrm{Liu}^{1,2}$ \\ ${ }^{1}$ Key Laboratory of Urban Land Resources Monitoring and Simulation Ministry of Land and Resources of China, Shenzhen, China- \\ ${ }^{2}$ Real Estate Assessment Center, Shenzhen, China-luliu.wh@gmail,com
}

KEY WORDS: liveability, housing price, Point of Interest

\begin{abstract}
:
This study proposes an index for cities in China to measure the liveability of real estate. This liveability index combines indicators from four dimensions including education, transportation, living facilities and entertainment, and can be quickly obtained by using data of Point of Interest, based on popular internet maps. Then, using Shenzhen as a sample city, correlation analysis has been adopted to examine the relationship between this liveability index and housing price. The results show that, the liveability index can well reflect the real-world situation of the city. Moreover, a weak but significant relationship can be found between liveability and the housing price. The results of this study not only can be used for urban residents to search a proper housing estate, but also can assistant urban planners and policy makers to get a general map of the
\end{abstract} spatial structure of the city.

\section{INTRODUCTION}

The fast process of urban development in China has sprouted blooming housing markets, especially in the so called first tire cities including Beijing, Shanghai, Guangzhou and Shenzhen. In the march of 2018 , the average housing price per square meter is over $\$ 10000$ for Beijing, and over $\$ 8000$ for Shanghai and Shenzhen, based on the data obtained from China real estate association. Within the city, the housing price has big discrepancy among various place(Wang, Shi et al. 2013). For instance, a house in the central business district is supposed to be more expensive than a house located in suburban region. The price of housing in the city can be effected by various factors, including the location, the house type, the public service surrounding it, the decoration and so on. A million of factors may related to the price of the house. Traditionally, to appraise the price of a house may need a specialist to make a field survey of the house, and judge its value by his previous experiences.

The impact factors of housing price may vary across countries, since people in different countries usually have unique interests about house(Jia, Wang et al. 2017). In western cities, the quality of the house itself may contribute a lot to the housing price, for instance, the number of the bath rooms, the landscapes and so on. However, in China, prices are more likely to be affected by the surrounding facilities and transportations, because people are more prone to live in the center city where people are easy reaching various facilities. Therefore, the livability, which indicates how much people would feel happy to live in this house may be measured differently in various country, and may have different effects to the housing price.

Although the impact factors of housing prices have been studied and well documented in the existing literatures(Pain and Westaway 1997, Selim 2009, Wang, Shi et al. 2013, Park and Bae 2015), few of them are focus on livability, and for China. In the past, the livability is difficult to be measured because of data limitation. In recent years, the emergence of many new datasets has make it possible to measure and use livability. Therefore, the objective of this paper is to propose an index in measuring the livability of houses located in different regions of a city, and explore its relationship with housing prices. The livability index can help people to quickly scan the city, and select the best few houses. Moreover, the results of the study can reveal that what kinds of livability aspects may the price are sensitive to. This paper utilized the points of interest (POI) data that are obtained from Baidu Map, and housing prices data obtained from website of real estate agents.
The paper is organized as follows: in section two, the datasets are introduced, and the proposed livability index are discussed, in section 3 , the results are interpreted, and we conclude in section 4 .

\section{STUDY AREA AND DATASET}

\subsection{Study Area}

Shenzhen is a major city in Guangdong Province. It is located in the south China, and is neighboring to Hong Kong. In the past decades, Shenzhen has experienced fast economic development, and it becomes a main financial center in China. This city has a population of over 15 million in the year 2014, but the average age is only around 30. It is a young city not only because the low average age, but also because it starts its urbanization from 1980, after it was set as a special economic zone of China.

\subsection{Data of POI}

The data of POI is obtained from Baidu map. Baidu map is an internet platform which provides people with information concerning automatic navigation. As the most popular map used by millions of people in China, it contains large amount of POI. These POIs cover a large range of city facilities, from railway station to bus station, from clinics to hospital, in other words, one can find nearly everything in a city by searching Baidu map. Therefore, the POI of Baidu map can be a functional map of the city, and can be a valuable data source to measure the livability of a city.

The Baidu map used in this work is obtained by developing tools. The data used in this study was obtained in October $10^{\text {th }}$ 2016. The POI data is construct by the location information, and a name describing the POI. These POIs are first classified into various classes including schools, hospitals, parking places and so on. A totally 122 classes are obtained. Some classes of the POI are selected to construct the livability Index.

\subsection{Data of Housing Price}

The housing prices are obtained from website of real estate. The housing price usually fluctuate over time. To ensure the consistency of price data, only the best seller month with most selling volume of the year 2016 is chosen as our datasets, which is October of 2016. The average price for each housing estate are calculated and used as the datasets for this study. As shown in Fig 1. The average housing prices 


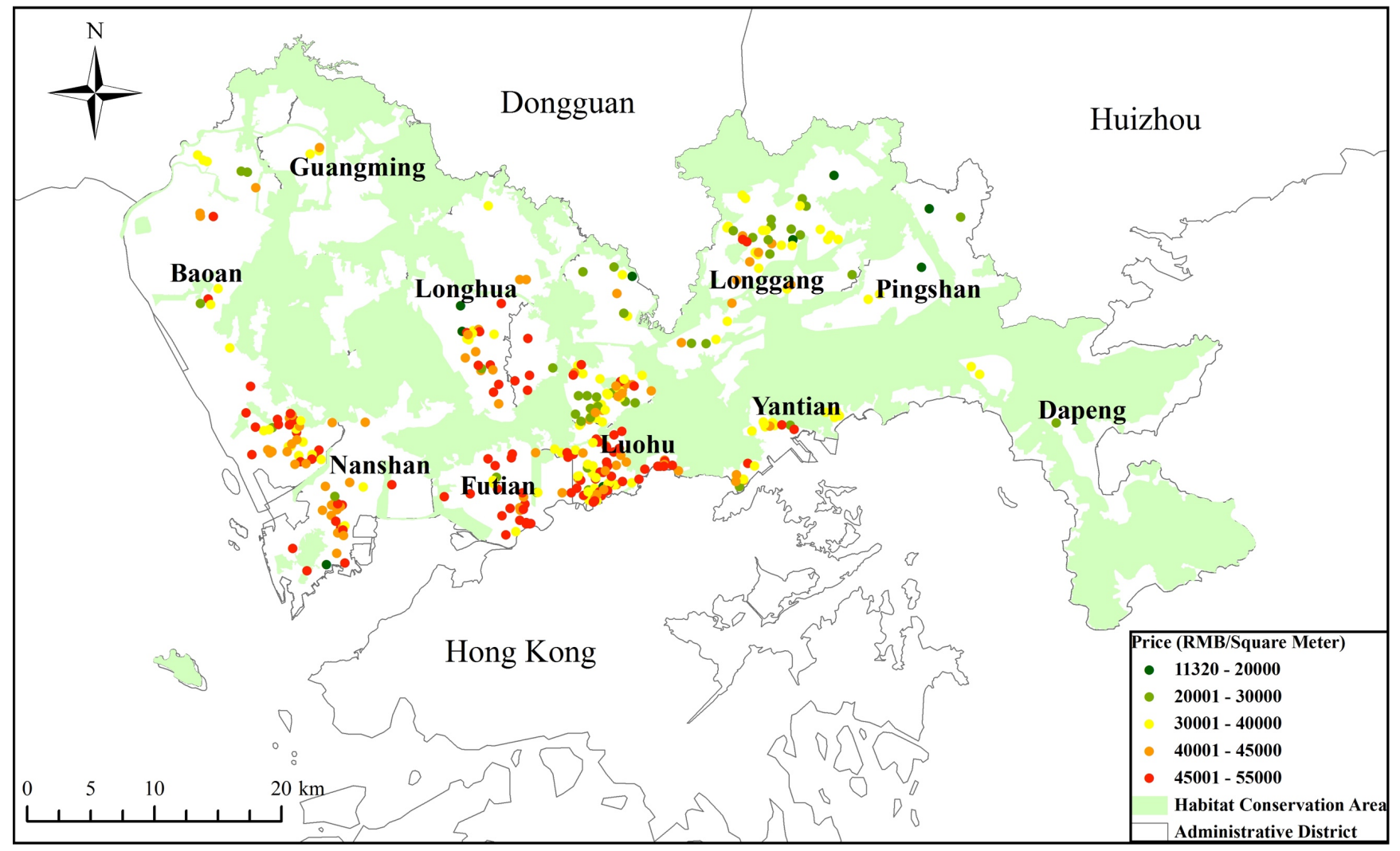

Figure 1. Prices of Housing Estate in Shenzhen (2016.10)

\section{LIVABILITY INDEX}

Based on the living style of city residents in China, the livability index can be constructed from four dimension, as discussed follows.

\subsection{Education}

Shenzhen is a very young city, with average age at around 30 . Education is something the residents very concerns about, because many of them have children at school age. The distance to kindergarden, primary school and middle school is an importatnt indicator of the livability in China. This indicator measures whether there is all three kinds of schools within 500 meters walking distance, thus to reveal how convenient the estate can get assess to various education facilities.

\subsection{Transportation}

In a big metropoli, the public transportation is very important for people to traval around the city, especially the subways, which can avoid problems of traffic jam. For this perspective, we calculate whether there is any subway station within $1 \mathrm{~km}$, and bus station within $500 \mathrm{~m}$ walking distance to decide the convenience of transportation of a housing estate.

\subsection{Living facilities}

The living facilities refers to restaurant, convenient store and supermarket. All these facilities can help residents to get assess to various necessaries. In Shenzhen, most people are busy working in the daytime, so easily get assess to dinners, and buy things are rather important for them. For this perspective, the number of restaurants, convenient stores and supermarkets are calculated within 300 walking distance to measure the convenience of accessibility to various living facilities.

\subsection{Entertainment}

The entertainment facilities include gyms, KTVs and cinemas. These facilities are very important for people, since their leisure time can be spent at these places. For young people, these facilities mean a lot for them to relax and make life more colorful. Therefore, the number of these entertainment facilities within $2 \mathrm{~km}$ of a housing estate is calculated to measure the accessibility.

The indicators for each dimension are listed in Table 1. For each indicator, the values are set to 0 or 1 , or are standardized using minmax normalization.

For each dimension, the value of the indicators are sumed us and divided by the number of indicators. Then the livable index is calculated by summing all four dimensions. Therefore, the final index actually have the four dimensions equally weighted.

\section{RESULTS AND INTERPRETATIONS}

\subsection{The Result of Liveability Index}

Fig. 2 shows the spatial map of livability index. The Shenzhen can be divided to two part, the original special economic zone, which includes Nanshan, Futian, Luohu and Yantian, and original 
non special economic zone, which includes the other seven districts. It can be seen from the map that, the houses with highest level of livability located mainly in Futian and Luohu.

\begin{tabular}{|l|l|l|}
\hline Dimension & indicator & calculation \\
\hline education & Kinder garden & 1 if any kindergarten is within $500 \mathrm{~m}$ walking distance, 0 otherwise \\
\cline { 2 - 3 } & Primary School & 1 if any Primary School is within $500 \mathrm{~m}$ walking distance, 0 otherwise \\
\cline { 2 - 3 } & Middle School & 1 if any Middle School is within $500 \mathrm{~m}$ walking distance, 0 otherwise \\
\hline Transportation & Subway Station & 1 if any Subway Station is within $1 \mathrm{~km}$ walking distance, 0 otherwise \\
\cline { 2 - 3 } & Bus Station & 1 if any Subway Bus Station is within $300 \mathrm{~m}$ walking distance, 0 otherwise \\
\hline Living Facilities & Restaurant & The number of Restaurant within $300 \mathrm{~m}$ walking distance \\
\cline { 2 - 3 } & Convenient Store & The number of Convenient Store within $300 \mathrm{~m}$ walking distance \\
\cline { 2 - 3 } & Super Market & The number of Super Market within $300 \mathrm{~m}$ walking distance \\
\hline & Gym & The number of Gym within $300 \mathrm{~m}$ walking distance \\
\cline { 2 - 3 } & KTV & The number of KTV within $300 \mathrm{~m}$ walking distance \\
\cline { 2 - 3 } & Cinema & The number of Cinema within $300 \mathrm{~m}$ walking distance \\
\hline
\end{tabular}

In districts of Nanshan, part of Yantian, Baoan and Longhua, the livability level is between 2-3, indicating that these places have been developed well for urban life. However, in some remote regions such as Pingshan, Dapeng and Guangming, the livability level is very low, which means that these places are not very convenient for the urban life.

\subsection{The results of correlation analysis}

To predict the housing price using a hedonic model usually needs to consider dozens of factors(Limsombunchai, Gan et al. 2004). In this study, only the livability is included, and the regression model only gets an $r$ square of 0.06 , and the model is not significant. Hence the Pearson correlation analysis has been adopted to clarify the relationship between price and livability of the housing estate.

As shown in Table 2, generally, the livability index has a significant relationship with housing price, which has a $\mathrm{r}$ value of 0.1814 . For the four dimension, education, transportation and entertainment facilities all has significant relationship with housing price, while living facilities has no significant relationship with housing price.

\begin{tabular}{|c|c|c|c|c|c|}
\hline r value & Education & Transportation & Living facilities & $\begin{array}{l}\text { Entertainment } \\
\text { Facilities }\end{array}$ & livability index \\
\hline Price & $0.1242 *$ & $0.1931^{*}$ & 0.0106 & $0.1953^{*}$ & $0.1814^{*}$ \\
\hline
\end{tabular}

\section{Table 2. Results of Correlation Analysis}

Moreover, it could be seen that, for all the four dimension, even if it has significant relationship with housing price, the $r$ value is rather low. That means, all these factors do not contribute much to the fluctuation of housing price over spaces in the city. By comparing Fig.1 and Fig.2, it can be clearly seen that, in northern part of Baoan, some places are with low livability level, but the housing price is rather high. This may because, the subway line come cross these regions, and the urban plans for these regions may make it a new center business district. People invest here with high price to gamble its future.

\section{CONCLUSION}

In this study, we proposed an index for cities in China to measure the livability of housing estate. This index can be quickly obtained by using data of city POI, based on popular internet maps. This livability index combines indicators from four dimensions including education, transportation, living facilities and entertainment. We applied it to Shenzhen, and the results are proved to reflect the real-world situation. This index can help people understand the livability of various housing estate located in different location of the city. On the other hand, it can help government and policy makers to get a general idea of the structure and infrastructures of the city, and thus make appropriate plans or policies to make the city a better place to live.

On the other hand, we explore the relationship between this livability and housing price. The result shows that a weak but significant relationship can be found. In other words, livability has some impact on the housing price, but not too much. The future urban plans, the rank of schools it associates with and other factors may contribute more to the spatial discrepancy of housing price.

This primary study has some limitations. First, a more comprehensive livability index should be designed to include more aspects of urban life, and questioners should be conducted to specify the weight of each indicators. Second, the price discrepancy of the housing price should be further explored by including more factors, such as distance to CBD, urban plans, the policies of each administrative district and so on. Thus, to find out the real factors that cause the fluctuation of housing price in space. 


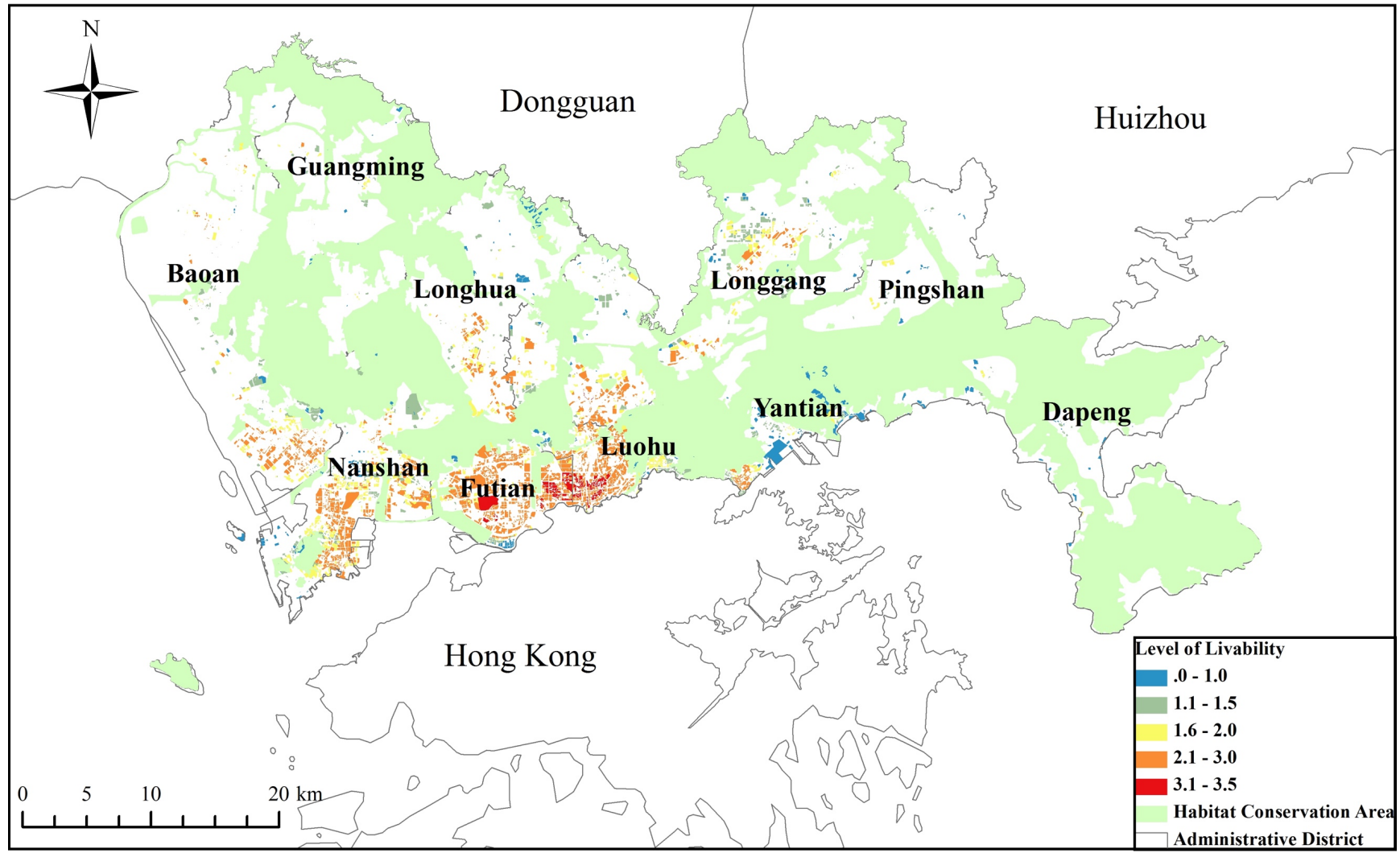

Figure2. Livability of Housing Estate In Shenzhen

\section{ACKNOWLEDGEMENT}

This research was financially supported by the Key Laboratory of Urban Land Resources Monitoring and Simulation Ministry of Land and Resource of China (Grant No. KF-2018-03-022).

\section{REFERENCES}

Jia, S., Y. Wang and G.-Z. Fan (2017). "Home-Purchase Limits and Housing Prices: Evidence from China." The Journal of Real Estate Finance and Economics.

Limsombunchai, V., C. Gan and M. Lee (2004). "House Price Prediction: Hedonic Price Model vs. Artificial Neural Network." American Journal of Applied Sciences 1(3).

Pain, N. and P. Westaway (1997). "Modelling structural change in the UK housing market: A comparison of alternative house price models." Economic Modelling 14(4): 587-610.

Park, B. and J. K. Bae (2015). Using machine learning algorithms for housing price prediction: The case of Fairfax County, Virginia housing data, Pergamon Press, Inc.

Selim, H. (2009). "Determinants of house prices in Turkey: Hedonic regression versus artificial neural network." Expert Systems with Applications 36(2): 2843-2852.

Wang, S., H. Shi and J. Zhang (2013). Commercial Housing Price Index Forecast Based on the Gray Model. International Conference on Construction and Real Estate Management. 